\title{
A NEW TETTIGIAN GENUS AND SPECIES FROM SOUTH AMERICA.
}

\author{
BY J. L, HANCOCK, CHICAGO, ILL.
}

The curious Tettigian here described from South America undoubtedly belongs to the subfamily Batrachidinae or Section VI of Professor Bolivar. From the group of which Tettigidea Scudder, and Paxilla Bolivar, form a part it is distinguished by the absence on the vertex of the frontal carina; the latter structure is represented, however, as a rudiment in the form of very small abbreviated lateral elevated ridges a little anterior to the supra ocular lobes of the head. It is the peculiar shortening of the last article of the posterior tarsus coincident with a lengthening of the first article which is specially characteristic in this new genus. These differences will neces. sitate a slight modification of existing tables of genera to receive it.

\section{Paurotarsus gen. nov.}

Body moderately long, slender, rugose. Face distinctly rounded anteriorly, slightly declined below. Vertex wide, considerably broader than one of the eyes; with a very small supra ocular lobe, on each side, separated behind from the broadened occiput by a little oblique fissure, front incompletely carinated; on each side close to the anterior inner border of the eyes, is a minute abbreviated, slightly converging carina, the space between these little latero-frontal carinae of the vertex obtusely sloping off in front; mid-carina abbreviated and very thin, slightly protuberant above, fusing with the smooth frontal costa.

In profile the head presents a distinctly rounded protuberant outline; as seen in front the frontal costa is strongly furcate, the branches widely and evenly diverging in their descension to the median ocellus. Eyes of moderate size, compresso-subtriangular in outline; ocelli distinctly showing in front of and a little above the middle of the eyes. Antennae (incomplete) slender, filiform, inserted in front of the eyes between the superior ocelli and the anterior inferior border of the eyes; apical article of maxillary palpi strongly ampliato-compressed. Pronotum scarcely convexed between the shoulders, anteriorly truncate, posteriorly long subulate, the pronotal process extending beyond the posterior femora; posterior border of lateral lobes feebly sinuate, the subhumeral sinus for the insertion of the elytra shallow. Elytra narrow; wings completely developed, extending beyond the process. Anterior femora slender, sulcate above; middle femoral carinae straight; external pagina of posterior femora rather rugose, the third article of the posterior tarsus very small, being less than one half the length of the first article, pulvilli subequal in length, straight below.

Paurotursus amazonus sp. nov. Fig. Ia, Ib, Ic, Id, Ie.

Body rugose, fuscous, first and second femora clouded with fuscous, tibiae annulated with fuscous. Vertex slightly tumid, nearly twice the breadth of one of the eyes, on each side provided with a small supra ocular lobe, divided behind from the broadened occiput by a minute oblique fissure, and just anterior to the supra ocular lobes are little abbreviated, slightly converging laterofrontal carinae which are separated anteriorly, apart about the width of one of the eyes, here the front is obtusely sloped off and not transversely carinated, mid-carina abbreviated, a little produced above, coalesc- 
ing anteriorly with the frontal costa; frontal costa strongly compresso-protuberant, advanced in front of the eyes about three fourths the length of one of them, presenting with the vertex a distinctly rounded outline in profile; viewed in front the frontal costa is quite widely furcate, starting opposite the upper margin of the eyes, the branches are evenly divergent and straight in their descension to the median ocellus. Eyes compresso-subtriangular in outline, the posterior ocelli are conspicuous midway between the anterior margins of the frontal knee of hind femora; lateral lobes of the pronotum very little diverging below, the inferior margin scarcely reflected, the posterior margin feebly sinuate, the posterior inferior angle nearly straight, superior or subhumeral sinus for the insertion of the elytra shallow. Elytra slender, apically obtusely rounded, externally punctate; wings fully developed extending beyond the pronotal process. Anterior femora sulcate above; middle femoral carinae straight, posterior femora quite slender, the tibia multispinose, first article of posterior tarsus

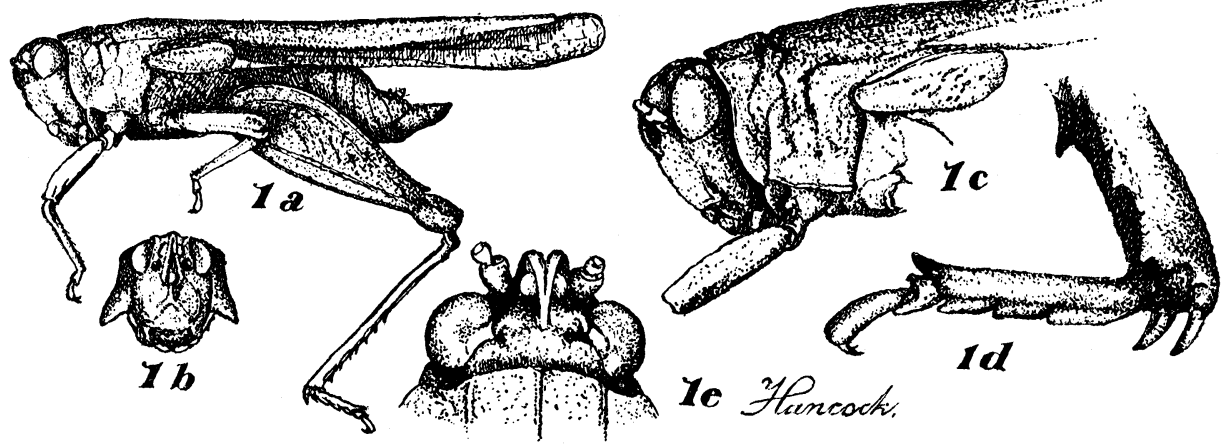

Fig. ra, Paurotarsus amazonus sp. n. Ib, same, front view of face and pronotum. rc, same, profile of body, greatly enlarged. Id, same, tarsus of posterior leg, enlarged. re, same, dorsal view of head, enlarged. Original, from nature by Dr. $\mathrm{H}$ ancock.

costa and the eyes, on a plane a little above their middle. Antennae filiform, maxillary palpi apically ampliato-compressed. Pronotum with the dorsal front margin truncate, posteriorly long and subulate, between the shoulders transversely scarcely convexed, strongly rugose; median carina distinctly elevated, nearly straight, interrupted near the front margin by a transverse suture, anterior lateral carinae short, subparallel; humeral angles strongly obtuse, apical process of pronotum extending beyond the a little more than twice as long as the third, the pulvilli subequally long, straight below. The subgenital plate of male as viewed from above acute conical, bifurcated at the extremity.

Length Body, $\delta$, pronotum $13.5 \mathrm{~mm}$. post. fem. $7.5 \mathrm{~mm}$. Entire length of body to apex of wings 16.5 millimeters.

Locality, Manaos, Amazon, South America. O. Staudinger.

Labelled Hedotettix. 

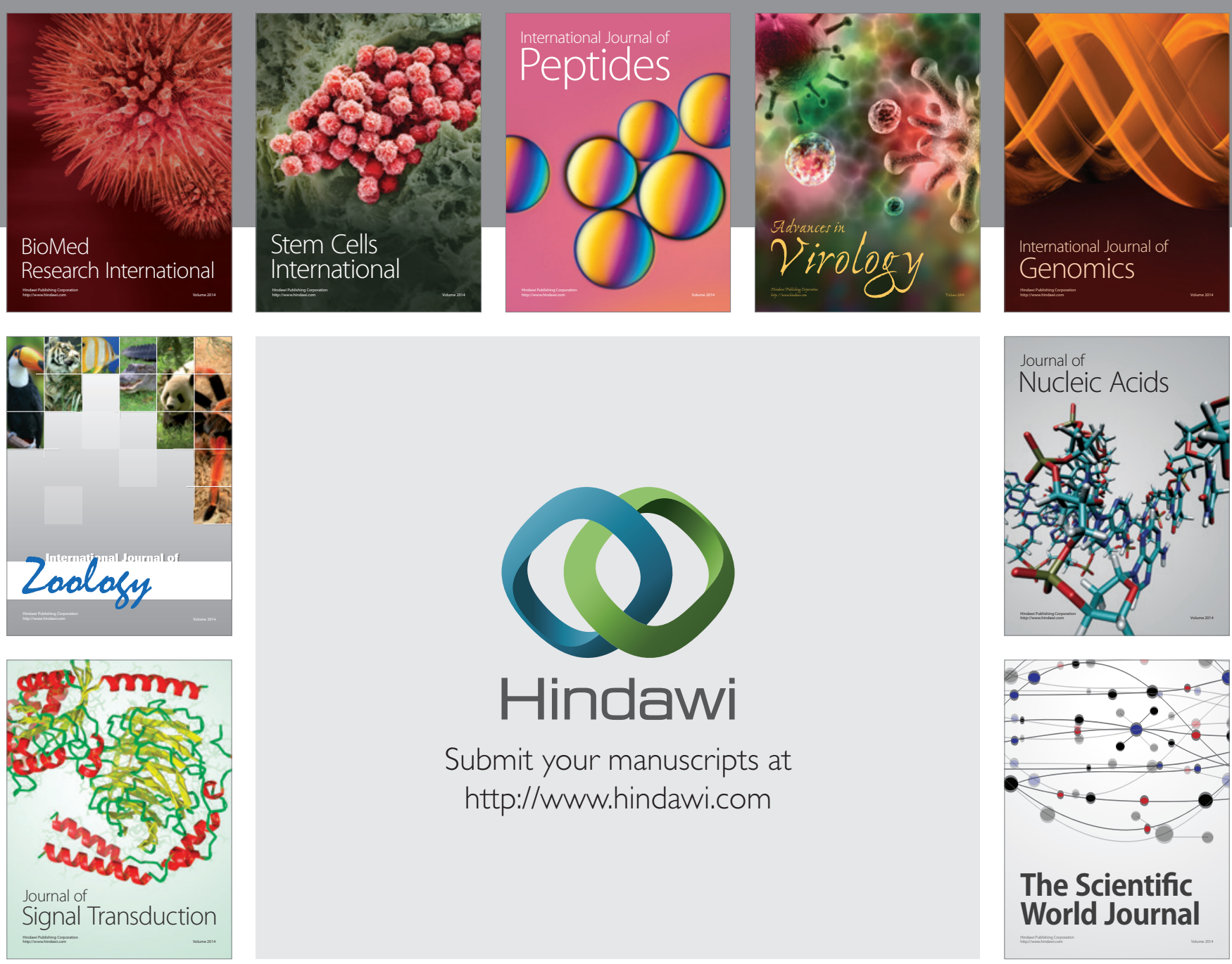

Submit your manuscripts at

http://www.hindawi.com
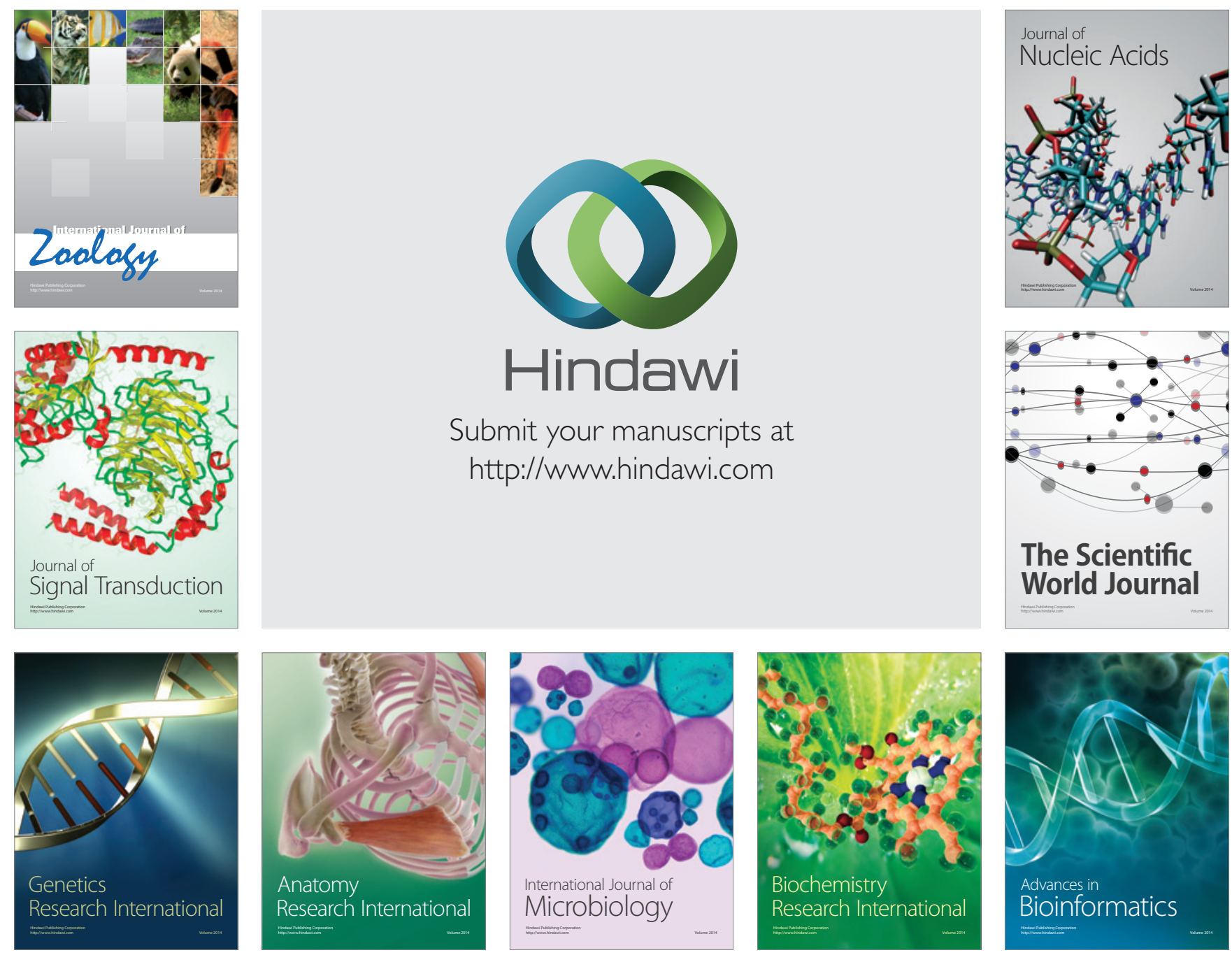

The Scientific World Journal
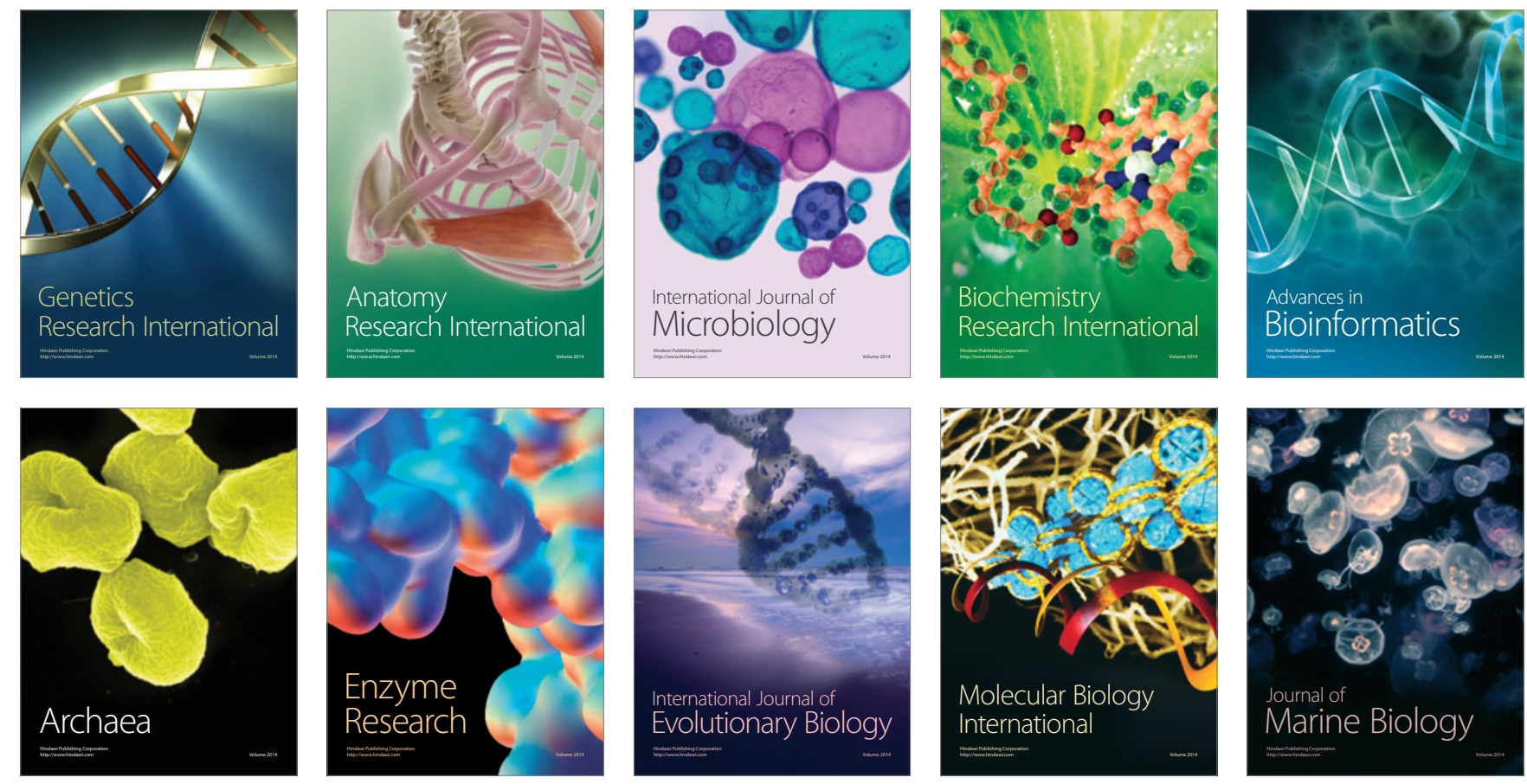